\title{
CALDEIRO DE REBITES DO SÍTIO ARQUEOLÓGICO DE FRIJÃo (BRAGA, NOROESTE DE PORTUGAL)
}

\author{
VÍTOR MANUEL FONTES SILVA ${ }^{(1)}$
}

Resumo:

\begin{abstract}
A finalidade deste trabalho passa por dar a conhecer os fragmentos de placas rebitadas descobertos no sítio arqueológico de Frijão, freguesia de Cunha, concelho e distrito de Braga.

O Frijão é uma estação arqueológica peculiar datável da Idade do Ferro quer pela sua localização, numa pequena plataforma da base da vertente sudeste do monte de Frijão, ou seja, contígua ao vale da ribeira de Levegada, quer pelo tipo de estruturas exclusivamente em materiais perecíveis.

As peças metálicas surgiram no contexto de uma escavação empresarial e encontravam-se nos depósitos de colmatação de uma estrutura subterrânea, onde havia grande concentração de cerâmica inseríveis entre os séculos IV e o II a.C., segundo a tabela de formas de Martins (1990).

Tendo em conta as particularidades dos fragmentos metálicos admitimos que pertencem a um caldeiro de rebites, peça relativamente rara durante este período cronológico.
\end{abstract}

Palavras-chave: Caldeiro de rebites, Idade do Ferro, Metalurgia, Noroeste da Península Ibérica.

\begin{abstract}
:
The cauldron of rivets of the archaeological place of Frijão (Braga, Northwestern Portugal)

The purpose of this paper is to disclose the discovery of fragments of riveted plaques found at the archaeological site of Frijão, parish of Cunha, county and district of Braga.

The Frijão is an Iron Age peculiar place, either for its location on a small platform at the basis of the southeast hill of Frijão (adjacent to the valley of Ribeira da Levegada), either by exclusive perishable materials structures.

The riveted plaques arose in the context of a commercial archaeological excavation, within the deposits of an underground structure, where there was a high concentration of pottery. These can be dated between the 4th and 2nd centuries BC, according to the ceramic typology of Martins (1990).

Taking into account the particularities of the metal fragments, we admit that they belong to a riveted cauldron, relatively rare during this chronological period in Northwestern Iberia.
\end{abstract}

Keywords: Riveted cauldron, Iron Age, Metallurgy, Northwestern Iberian Peninsula.

Received: 1 August, 2013; Accepted: 13 October, 2013

\section{HISTORIAL}

A estação arqueológica de Frijão foi identificada por Rui Barbosa da empresa Palimpsesto - Estudo e Preservação do Património Cultural, Lda., no ano de 2003, aquando dos trabalhos de acompanhamento arqueológico dos locais selecionados para extração : Troço Nine-Braga e Estação de Braga».

Devido à quantidade de artefactos que as movimentações de terra puseram a descoberto, foi determinada a escavação arqueológica do locus, em 2004, tarefa que ficou a cargo de Sandra Salazar Ralha, ao serviço da empresa Archeoestudos, Investigação Arqueológica, Lda. Deste trabalho resulttttou um relatório de escavação entregue e aprovado pela tutela (RALHA, 2004). Com base na leitura deste documento pudemos aferir que foram realizadas quatro sondagens arqueológicas neste local, numa área de $121 \mathrm{~m}^{2}$. No decorrer dos trabalhos foram exumados artefactos cerâmicos, metálicos e líticos, em quantidade significativa, embora alvo de estudo parcial no referido relatório de escavação (RALHA, 2004).

Apesar dos materiais arqueológicos terem dado entrada no Museu Regional de Arqueologia D. Diogo de Sousa (MDDS), em Braga e, muitos deles, constarem da exposição permanente, este local nunca foi alvo de estudo monográfico, tendo apenas sido inventariado (BARBOSA \& AZEVEDO, 2004-2005; FERREIRA, 2012), motivo pelo qual, em 2013, iniciámos o seu estudo no âmbito de um projeto de mestrado intitulado $A$ Estação Arqueológica da Idade do Ferro de Frijão (Braga, Norte de Portugal). 


\section{LOCALIZAÇÃO ADMINISTRATIVA, CONTEXTO FÍSICO, AMBIENTAL E ARQUEOLÓGICO}

A estação arqueológica de Frijão localiza-se no lugar do mesmo nome, pertencente à freguesia de Cunha, concelho e distrito de Braga, antiga província do Minho, no norte de Portugal.
As coordenadas geográficas, no sistema WGS 84 , são as seguintes: Latitude $41^{\circ} 29^{\prime} 33^{\prime \prime} \mathrm{N}$; Longitude $8^{\circ} 31^{\prime} 16^{\prime}$ ' W (Fig.1).

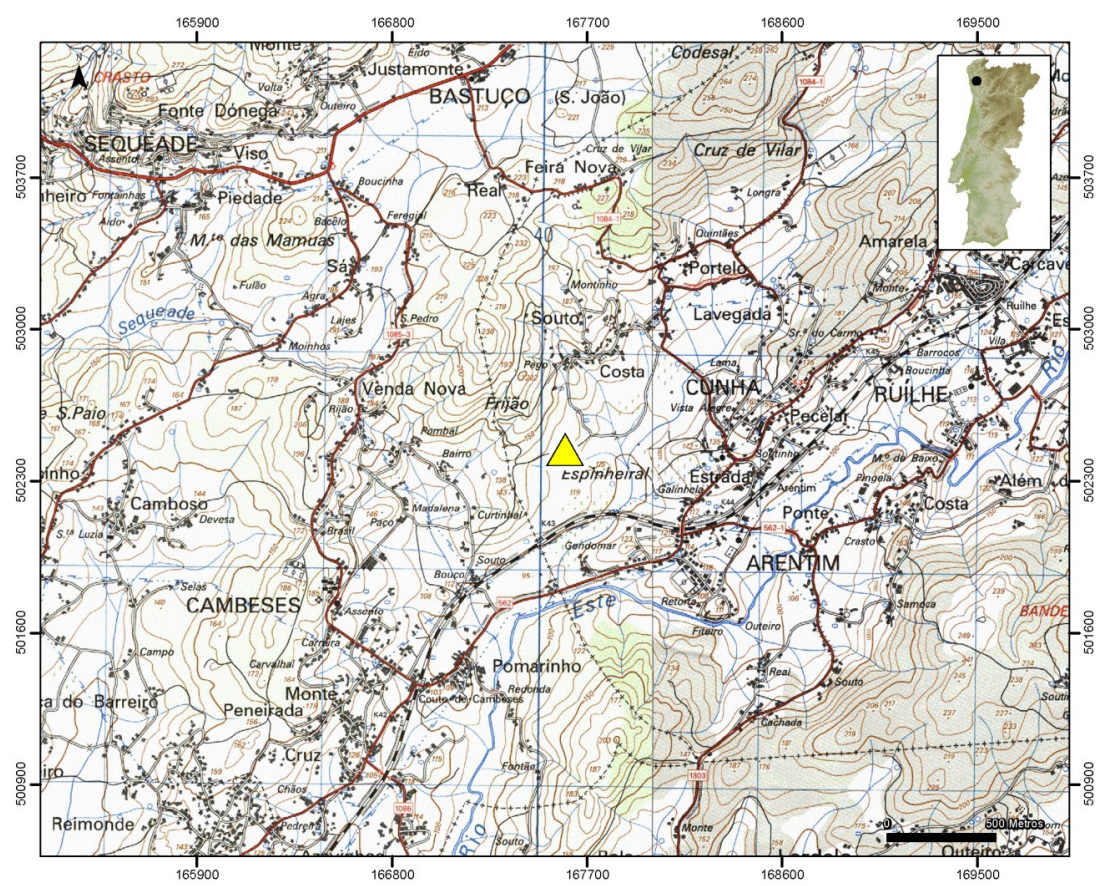

Fig.1. Localização do sítio arqueológico na Carta Militar de Portugal, folha 69-70, na escala 1:25 000, Coordenadas GCS, Datum de Lisboa, Hayford-Gauss.

Fig.1. Location of the archaeological site of Frijão in the Military Chart of Portugal, sheets 69-70, scale 1:25 000, Coordinate System GCS, Datum de Lisboa, Hayford-Gauss.

O Frijão encontra-se numa pequena plataforma existente na base da vertente sudeste do monte de Frijão, a uma altitude de $140 \mathrm{~m}$ e nas imediações de um vale aberto com potencialidades agrícolas (Fig. 2). A cerca de $150 \mathrm{~m}$ para sul e para oeste deste local existem duas linhas de água que drenam para a ribeira de Levegada, subsidiária do rio Este e parte integrante da bacia hidrográfica do rio Ave.

Analisando a Carta Geológica de Portugal $\mathrm{n}^{\circ}$ 5C, na escala 1:50 000, o substrato rochoso do local é constituído por granitos porfiróides de grão grosseiro a médio, por vezes aflorando à superfície, principalmente a Oeste da estação arqueológica (MEDEIROS \& TEIXEIRA 1969).

Atualmente o local está destruído, mas o coberto vegetal nas vertentes do monte é do tipo arbóreo e arbustivo, onde há o predomínio do pinheiro bravo, do eucalipto, do carvalho e do sobreiro, e a ocorrência de urzes, fetos e giestas. No que diz respeito a outros vestígios arqueológicos próximos estão identificadas e cartografadas as estações do Espinheiral I (NeolíticoMdio/Final?), do Frijão I (Idade do Bronze), do Pego I e II (Idade do Bronze e Idade
Média/Moderna) e do Espinheiral II (Romano) (BARBOSA \& AZEVEDO 2004-2005; FERREIRA 2012), portanto estações que não seriam contemporâneas do Frijão. Os povoados da Idade do Ferro conhecidos numa área de $15 \mathrm{~km}$ são 12 , diversas entre si em termos de localização no espaço (Tabela 1). Apenas alguns foram escavados pelo que o conhecimento das suas fases cronológicas, em pormenor, é muito deficitário, sendo possível que nem todos tenham sido contemporâneos do lugar do Frijão.

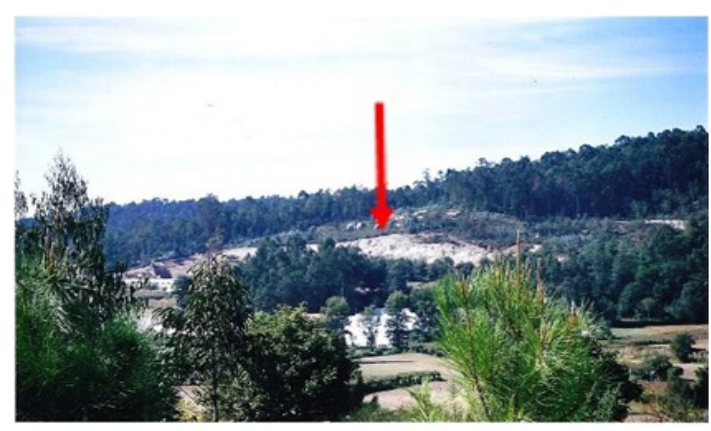

Fig. 2. Aspeto do lugar de Frijão (Foto: Ralha, 2004). Fig. 2. The Frijão locus (Photo: Ralha, 2004). 
Tabela 1. Inventário dos povoados da Idade do Ferro próximos de Frijão Table 1. Inventory of Iron Age settlements near Frijão

\begin{tabular}{|c|c|c|c|c|c|}
\hline Id & Toponímia & Localidade & $\begin{array}{c}\text { Distância em } \\
\text { relação ao Frijão }\end{array}$ & Cronologia & Referências Bibliográficas \\
\hline 1 & Crasto (Priscos) & Priscos, Braga & $5 \mathrm{~km}$ para este & Idade do Ferro & Barbosa \& Azevedo 2004-2005; Ferreira 2012 \\
\hline 2 & S. Bento & Vimieiro, Braga & $6,5 \mathrm{~km}$ para este & $\begin{array}{l}\text { Idade do Bronze; Idade } \\
\text { do Ferro }\end{array}$ & Barbosa \& Azevedo 2004-2005; Ferreira 2012 \\
\hline 3 & $\begin{array}{l}\text { Monte das Cal- } \\
\text { das }\end{array}$ & Gondizalves, Braga & $9 \mathrm{~km}$ para nordeste & $\begin{array}{l}\text { Idade do Ferro, Romano, } \\
\text { Medieval }\end{array}$ & $\begin{array}{l}\text { Bellino 1909; Cunha 1947,1975; Teixeira 1955/1956; } \\
\text { Martins 1990; Fontes 1993; Bettencourt 1999; Carvalho } \\
\text { 2008; Ferreira 2012 }\end{array}$ \\
\hline 4 & $\begin{array}{l}\text { Monte da Falper- } \\
\text { ra }\end{array}$ & Esporões, Braga & $15 \mathrm{~km}$ para este & $\begin{array}{l}\text { Bronze Final, Ferro, } \\
\text { Romano, Alta Idade } \\
\text { Média }\end{array}$ & $\begin{array}{l}\text { Sarmento 1933; Bellino 1909; Cunha 1948; 1953-54; } \\
\text { 1975; Sousa 1968-1970; Teixeira et al. 1977; Castro et l. } \\
\text { 1983; Feio 1984; Silva 1986; Martins 1990; Queiroga } \\
\text { 2003; Dinis 1993; Fontes 1993; Bettencourt 1999; } \\
\text { Carvalho 2008; Ferreira 2012 }\end{array}$ \\
\hline 5 & Monte Redondo & Guizande, Braga & $\begin{array}{l}8,5 \mathrm{~km} \text { para nor- } \\
\text { deste }\end{array}$ & Idade do Ferro, Romano & $\begin{array}{l}\text { Vasconcelos 1897, 1905,1913; Bellino 1909; Teixeira } \\
\text { 1955; Encarnação 1970; Cunha 1975; Castro et al. 1980; } \\
\text { Silva 1986; Calo Lourido 1994; Queiroga 2003; Dinis } \\
\text { 1993; Fontes 1993; Carvalho 2008; Ferreira 2012 }\end{array}$ \\
\hline 6 & Alto das Eiras & $\begin{array}{l}\text { Pousada de Sarama- } \\
\text { gos, Vila Nova de } \\
\text { Famalicão }\end{array}$ & $\begin{array}{l}11,5 \mathrm{~km} \text { para } \\
\text { sudeste }\end{array}$ & Idade do Ferro, Romano & $\begin{array}{l}\text { Sarmento 1933, 1970; Queiroga 1983, 2003; Calo } \\
\text { Lourido 1994; Dinis 1993; Carvalho 2008; Ferreira } 2012\end{array}$ \\
\hline 7 & $\begin{array}{l}\text { Castro de Ver- } \\
\text { moim }\end{array}$ & $\begin{array}{l}\text { Vermoim, Vila Nova } \\
\text { de Famalicão }\end{array}$ & $\begin{array}{l}11 \mathrm{~km} \text { para sudes- } \\
\text { te }\end{array}$ & $\begin{array}{l}\text { Idade do Ferro, Romano, } \\
\text { Medieval? }\end{array}$ & $\begin{array}{l}\text { Costa 1706-1712; 1868-1869; Sarmento 1933; Cardoso } \\
\text { 1932; 1972; Rosário 1973; Almeida 1974; Cunha 1975; } \\
\text { Queiroga 1983, 1995a, 1986aa, 2003; Silva 1986; Calo } \\
\text { Lourido 1994; Dinis 1993; Carvalho 2008; Ferreira 2012 }\end{array}$ \\
\hline 8 & $\begin{array}{l}\text { Castro de Santa } \\
\text { Cristina }\end{array}$ & $\begin{array}{l}\text { Requião, Vila Nova } \\
\text { de Famalicão }\end{array}$ & $\begin{array}{l}11 \mathrm{~km} \text { para sudes- } \\
\text { te }\end{array}$ & $\begin{array}{l}\text { Idade do Ferro, Medie- } \\
\text { val? }\end{array}$ & Queiroga 1992; Dinis 1993; Carvalho 2008; Ferreira 2012 \\
\hline 9 & Castro do Cruito & $\begin{array}{l}\text { Vale S. Martinho, } \\
\text { Vila Nova de Famali- } \\
\text { cão }\end{array}$ & $\begin{array}{l}10,5 \mathrm{~km} \text { para } \\
\text { sudeste }\end{array}$ & Idade do Ferro & Queiroga 1992; Dinis 1993; Carvalho 2008; Ferreira 2012 \\
\hline 10 & Castro da Bóca & $\begin{array}{l}\text { Vale S. Cosme, Vila } \\
\text { Nova de Famalicão }\end{array}$ & $\begin{array}{l}6,8 \mathrm{~km} \text { para sudes- } \\
\text { te }\end{array}$ & Idade do Ferro & Queiroga 1992; Dinis 1993; Carvalho 2008; Ferreira 2012 \\
\hline 11 & $\begin{array}{l}\text { Castro das Ermi- } \\
\text { das }\end{array}$ & $\begin{array}{l}\text { Jesufrei, Vila Nova de } \\
\text { Famalicão }\end{array}$ & $3,5 \mathrm{Km}$ pra sul & Idade do Ferro, Romano & $\begin{array}{l}\text { Brandão 1889-1892; Queiroga 1983; 1985b; 1985c; } \\
\text { 1986b; 2003; Silva 1986; Pautreau \& Queiroga } 1990 \text {; } \\
\text { Figueiral 1990; Dinis 1993; Carvalho 2008; Ferreira 2012 }\end{array}$ \\
\hline 12 & Castro do Facho & $\begin{array}{l}\text { Calendário, Vila Nova } \\
\text { de Famalicão }\end{array}$ & $10,5 \mathrm{~km}$ para sul & $\begin{array}{l}\text { Bronze Final, Ferro, } \\
\text { Romano }\end{array}$ & $\begin{array}{l}\text { Teixeira \& Medeiros 1965; Queiroga 1983, 2003; Dinis } \\
\text { 1993; Carvalho 2008; Ferreira } 2012\end{array}$ \\
\hline
\end{tabular}

\section{CONDIÇÕES DO ACHADO}

Os fragmentos metálicos de caldeiro, num total de 71 fragmentos, foram encontrados, essencialmente, nas unidades estratigráficas que correspondiam ao enchimento de um valado ou de um fosso (Fig. 3). Estes foram recolhidos na unidade estratigráfica (UE) 107/402, num total de 64 fragmentos, e na UE 403 onde se descobriram, apenas, 3 fragmentos.

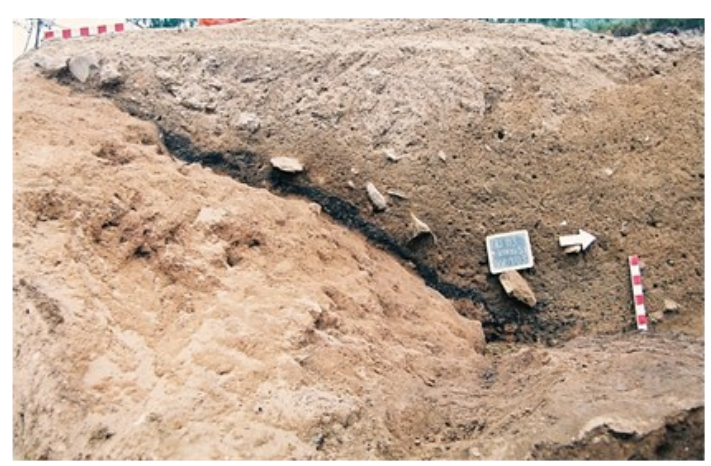

Fig. 3. Valado/Fosso do Sector I, quadrícula 1. Na base, a negro, é visível a UE 107/402 (Foto: Ralha, 2004).

Fig. 3. Trench of the Sector I, grid 1. At the bottom it is visible the layer 107/402 (on black) (Photo: Ralha, 2004).

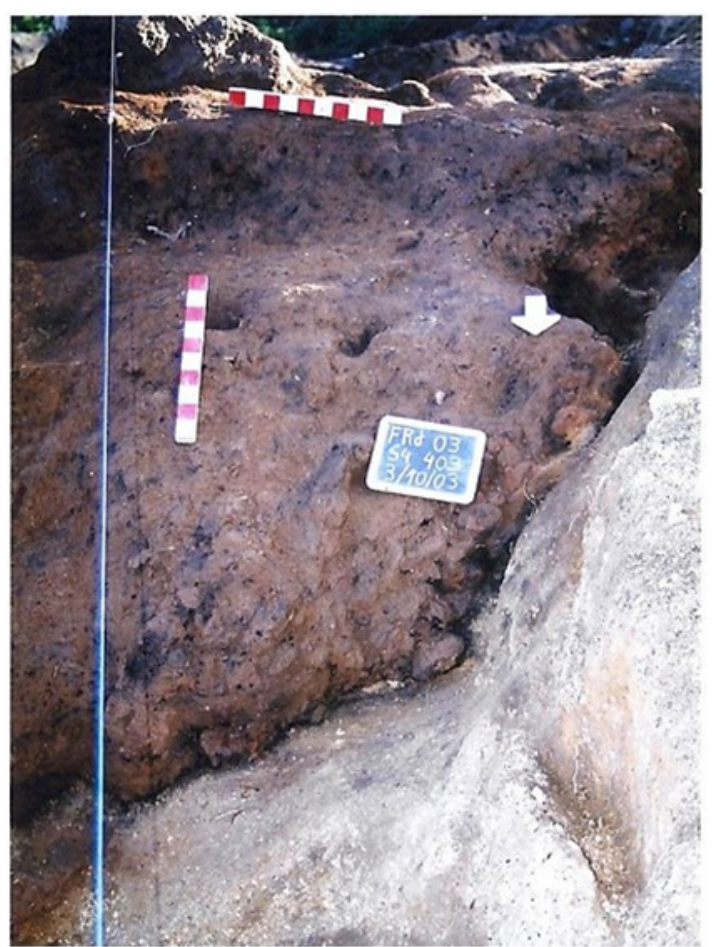

Fig. 4. UE 403, Sector I, quadrícula 4 onde apareceram parte dos achados metálicos (Foto: Ralha, 2004).

Fig. 4. Layer 403, Sector I, grid 4 where appears part of metal fragments (Photo: Ralha, 2004). 
A UE 107/402 correspondia a depósitos de inúmeros carvões e cinzas, localizada no fundo da estrutura em negativo. A UE 403, composta, essencialmente, por argila (derrube/destruição de uma estrutura perecível?) preenchia grande parte do enchimento do fosso ou valado (Fig. 4).

Os restantes 4 achados metálicos descobriram -se nas UE's 109 e 401 correspondentes a terras descontextualizadas pela ação da maquinaria que revolveu o local durante as obras de extração de saibro.

Com base no estudo técnico e morfológico dos materiais cerâmicos associados à UE 107/402, e consoante a tabela de formas de Martins (1990), consideramos que esta estrutura foi colmatada entre os séculos IV e II a.C. (SILVA 2013).

\section{DESCRIÇÃO DOS ACHADOS}

Foram exumados 71 fragmentos metálicos classificáveis em 54 pequenas placas rebitadas; 5 rebites; 1 vareta e 11 peças indeterminadas.

Para o estudo deste conjunto, tivemos em conta as suas características técnicas e formais e o seu estado de conservação.

Dos 54 fragmentos de placas rebitadas, verificámos que todos eram muito pequenos, variando entre os $51 \mathrm{~mm}$ e os $50 \mathrm{~mm}$ de comprimento e entre os $3,69 \mathrm{~mm}$ e os $0,76 \mathrm{~mm}$ de espessura, correspondendo as partes mais espessas às zonas de junção de placas que se encontravam em melhor estado de preservação (Fig. 5).

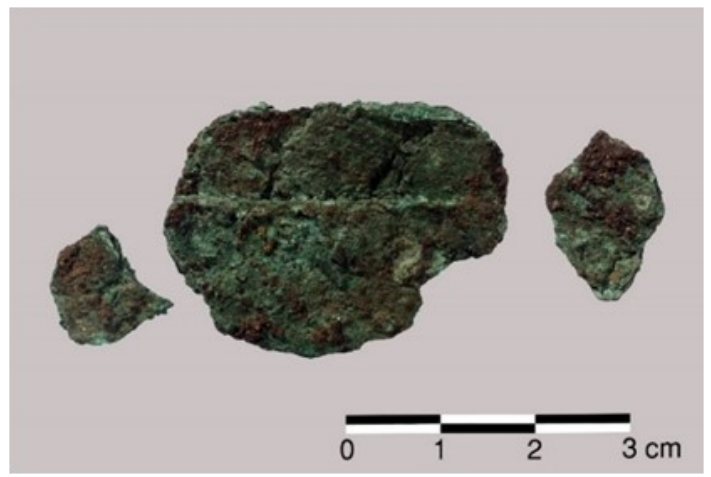

Fig. 5. Anverso de placas rebitadas - Inv. No 2004/0658 (Foto: Manuel Santos, MDDS, Braga).

Fig. 5. Obverse of the riveted plaques - Inv. $N^{o}$ 2004/0658 (Photo: Manuel Santos, MDDS, Braga).

Todos os rebites empregues possuíam um formato paralelepipédico, com secção quadrangular e com espessura entre $2,49 \mathrm{~mm}$ a $4,98 \mathrm{~mm}$. A sua altura variava entre os $1,18 \mathrm{~mm}$ e os $8,35 \mathrm{~mm}$ (Fig. 6).

É de registar que, na superfície interna das placas, nota-se perfeitamente a martelagem dos rebites que serviu para a junção das placas (Fig. 5). Muitas destas placas apresentam carvões incrustados (Fig. 5).

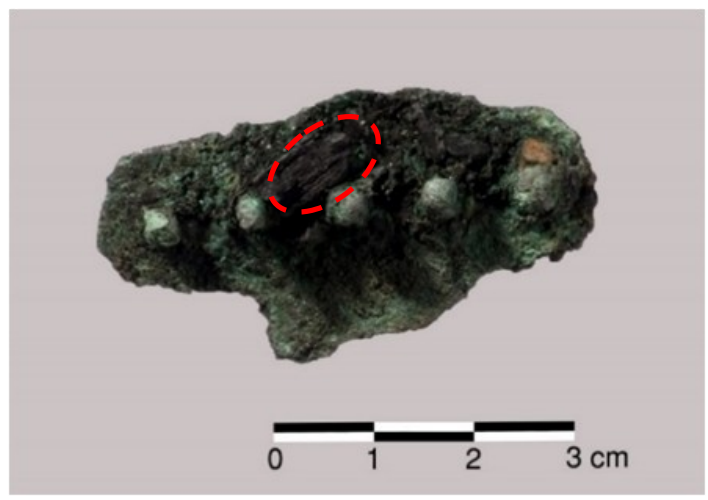

Fig. 6. Superfície externa de uma placa rebitada onde se podem ver os rebites e aderência de carvões - Inv. $\mathrm{N}^{\circ}$ 2004/0658 (Foto: Manuel Santos, MDDS, Braga).

Fig. 6. Outer surface of a riveted plaque where we can see the rivets and the adherence of the charcoals - Inv. $N^{\circ}$ 2004/0658 (Photo: Manuel Santos, MDDS, Braga).

Os 5 rebites encontrados eram grosseiramente paralelepipédicos, com seção quadrangular, apresentando uma variação de $2,15 \mathrm{~mm}$ a $6,07 \mathrm{~mm}$ de altura e de $2,30 \mathrm{~mm}$ a $3,20 \mathrm{~mm}$ de espessura na base, sendo a espessura da cabeça de $5,57 \mathrm{~mm} \mathrm{a}$ $7,32 \mathrm{~mm}$.

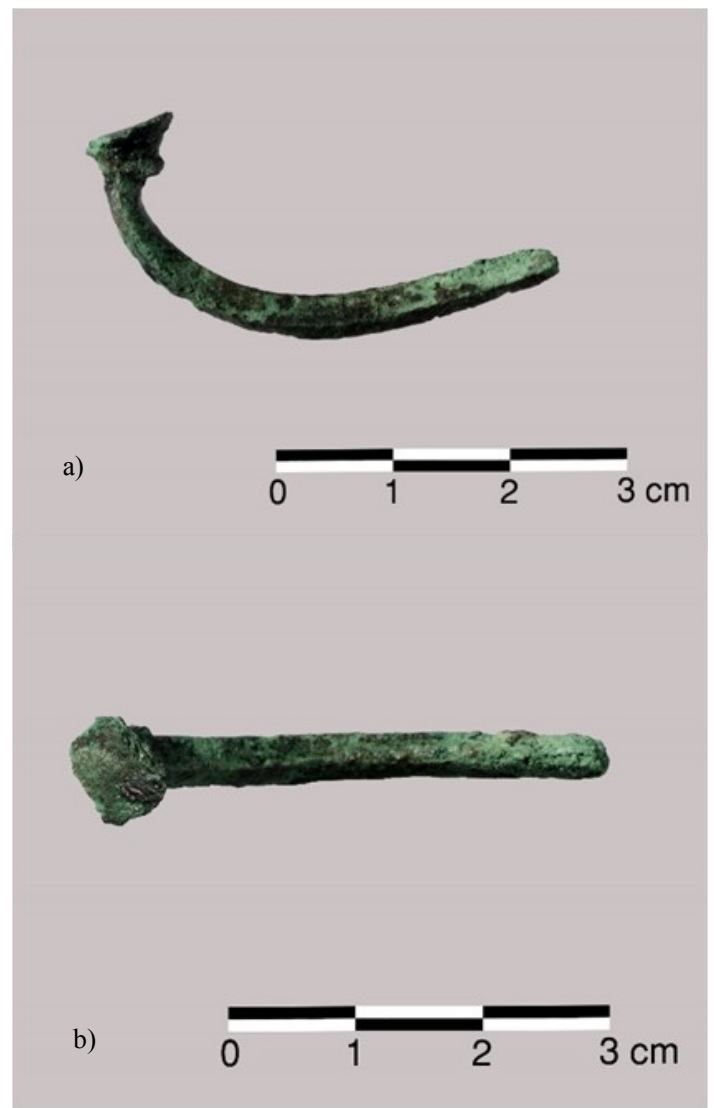

Fig. 7. a) Fragmento de provável asa lateral de caldeiro, vista de lado. b) Fragmento de provável asa lateral de caldeiro Inv. No 2004/0666 (Foto: Manuel Santos, MDDS, Braga).

Fig. 7. a) Fragment of probable lateral wing of cauldron (Lateral view). b) Fragment of probable lateral wing of cauldron - Inv. $\mathrm{N}^{\circ}$ 2004/0666 (Photo: Manuel Santos, MDDS, Braga). 
A vareta, fragmentada, de seção mais ou menos quadrangular, tinha $33,28 \mathrm{~mm}$ de comprimento por $3,34 \mathrm{~mm}$ de espessura. A extremidade do objeto foi acoplada, através de um processo de junção térmico e mecânico, a uma placa partida, ainda com $8,09 \mathrm{~mm}$ de comprimento por $0,97 \mathrm{~mm}$ de espessura (Fig. 7).

Para além destes objetos foram encontrados 11 fragmentos metálicos indeterminados devido às suas reduzidas dimensões e estado avançado de corrosão.

Apesar de não termos análises de composição química para determinar o tipo de liga usada no fabrico destas peças, a observação macroscópica e os paralelos existentes para este tipo de fragmentos, leva-nos a considerar que seriam de bronze.

\section{CONSIDERAÇÕES FINAIS}

Tendo em conta as características das 54 pequenas placas rebitadas, dos 5 rebites e da vareta, defendemos, com grande probabilidade, que se tratam de fragmentos de um caldeiro de rebites, muito destruído pela ação do fogo. De notar a grande similitude formal entre as placas e os rebites, assim como das suas condições de destruição. A vareta pertenceria, presumivelmente, a uma das pegas laterais do objeto metálico (SILVA 2013).

Os caldeiros de rebites são recipientes de bronze de fundo curvo e forma cónica ou semiovoidal mais ou menos achatada. São elaborados através da união de chapas, no mínimo três, cuja junção é realizada através da costura de ostentosos rebites na horizontal e vertical, pouco espaçados entre si. Todos eles apresentam um sistema de suspensão (ARMADA PITA 2005, 2008).

Quando falamos de caldeiros de rebites lembramo-nos dos exemplares de grandes dimensões e de bom estado de conservação, como o de Lois (SHUBART 1961 in ARMADA PITA 2005). No entanto, o de Frijão, tal como os caldeiros exumados na Península Ibérica, apresentam um estado de preservação bastante fragmentário, o que dificulta a reconstrução da sua ou suas morfologias (ARMADA PITA 2005).

Tendo em conta os achados destes recipientes metálicos na Ibérica, podemos referir que surgem, habitualmente, em contextos muito diversificados, desde povoado, depósitos, grutas ou galerias subterrâneas (minas) e em depósitos funerários (ARMADA PITA 2005).

Em termos cronológicos, os caldeiros de rebites surgem no noroeste peninsular durante o Bronze Final. Os achados mais antigos são os dos povoados do Coto da Pena I, em Caminha, dos finais do II, inícios do I milénios AC
(SIlva 1986) e da Santinha I, em Amares, do séc. X a.C. (Bettencourt 1999, 2001b). Porém, estas peças tiveram uma longa diacronia de manufatura e utilização, perdurando pela Idade do Ferro (BETTENCOURT 2001a; ARMADA PITA 2005), tal como se comprova, uma vez mais, com os achados no Frijão, inseríveis no que em Portugal se considera, ainda, Ferro Antigo (MARTINS 1990; BETTENCOURT 1999) e na Galiza, Ferro Médio (REY CASTIÑEIRAS 1992; GONZÁlEZ RUIBAL 2006; AYÁN VILA 2011). Tal continuidade formal entre este período e o Bronze Final revela provável continuidade de ritos (BETTENCOURT 2001a).

Os caldeiros de rebites estão associados a testemunhos de consumo intensivo de alimentos e de bebidas, no âmbito de cerimónias que se crê de uma enorme carga simbólica por parte das comunidades do passado, não sendo, por isso, atos comuns do quotidiano (ARNOLD 1993; GonZÁlez RuIBAL 2006; ARMADA PITA 2005, 2008). Nesta perspetiva, coloca-se a questão de como interpretar estes achados e o próprio local do Frijão.

Pelas condições estratigráficas em que foram encontrados os diferentes fragmentos de caldeiro não podemos considerar que esta peça tivesse sido depositada inteira no interior de um valado ou fosso, ou seja, que tivesse sido um depósito fundacional. No entanto, não excluímos a possibilidade de, após a sua utilização primária, ter sido destruído pelo fogo, quer pelo seu estado de fragmentação, quer por se associar maioritariamente a depósitos de carvões e de cinzas, e, posteriormente, depositado no interior da estrutura em negativo, em associação com restos de outros artefactos.

De notar a sua associação com um número considerável de recipientes cerâmicos designados por panelas de asa interior, também relacionadas com a preparação de alimentos, segundo Martins (1990), permite supor que estaríamos face a restos materiais de um banquete comunal, tal como já tínhamos defendido (SILVA 2013). Este teria ocorrido num lugar isolado e longe dos locais de residência, dadas as características gerais deste sítio e a distância a que se conhecem povoados que com ele tem interrelação visual (Fig. 8), como é o caso do da Falperra, das Ermidas e do Facho, todos com ocupações da Idade do Ferro genericamente contemporâneas do Frijão.

De frisar que a quebra ou destruição intencional de objetos (BRUDENELL \& COOPER 2008; AYÁN VILA 2011) tem sido atribuída a atos celebrativos, o que constitui mais um dado a favor da hipótese de estarmos perante o que resta de um banquete cerimonial da Idade do Ferro Inicial. 


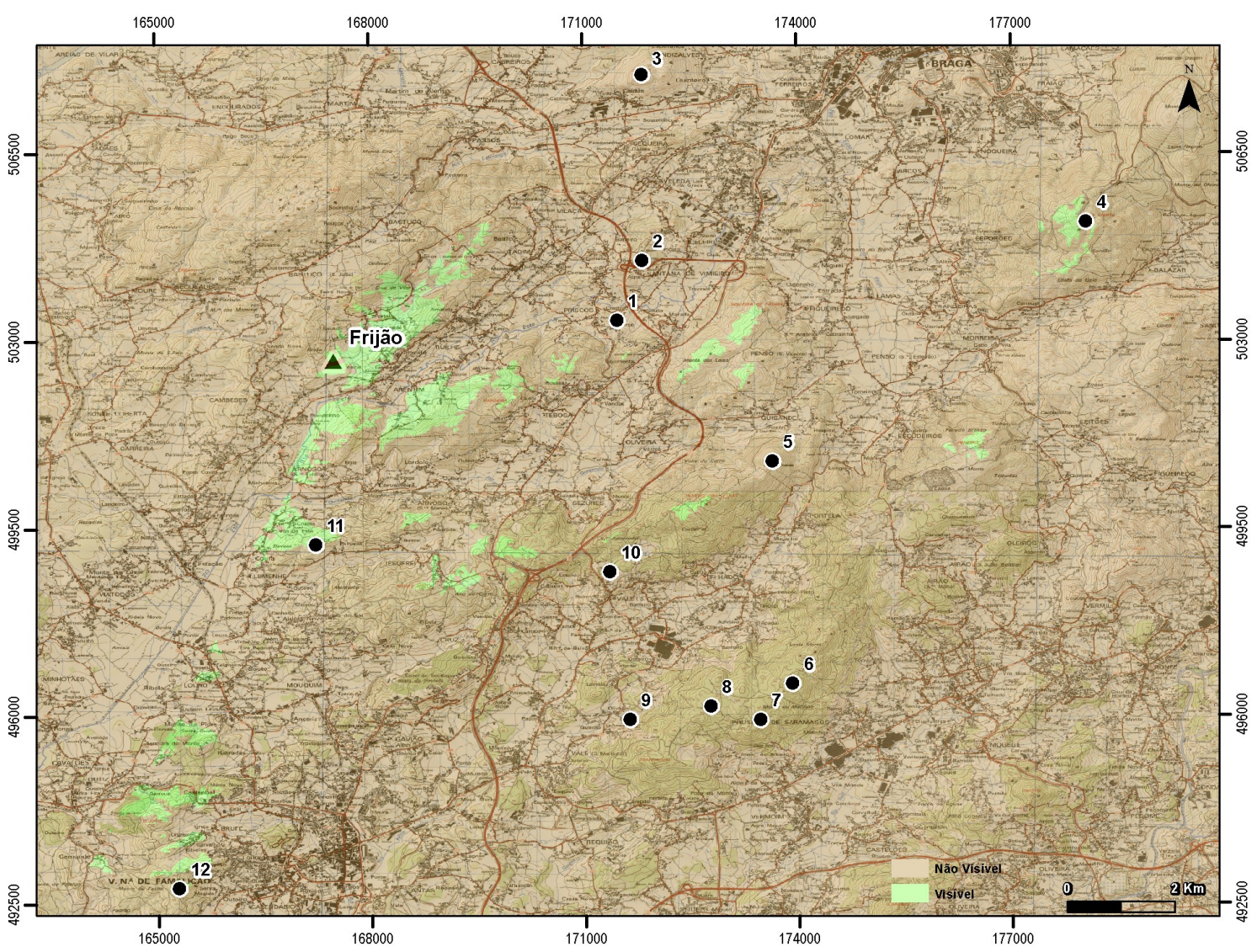

Fig. 8. Localização do lugar do Frijão no contexto do povoamento da Idade do Ferro no vale do rio Este, a partir da Carta Militar de Portugal, à esc. 1:25. 000, folhas 69, 70, 83 e 84, e no Modelo Digital de Terreno, Coordenadas GCS, Datum de Lisboa, Hayford-Gauss. A verde, assinalam-se as áreas de visibilidade a partir do Frijão. Os povoados que ficam no seu campo visual são os da Falperra (4), Ermidas (11) e Facho (12).

Fig. 8. Location of the Frijão in the context of Iron Age settlements in the valley of the Este river, in the Military Chart of Portugal (scale 1:25. 000, sheets 69,70,83 and 84) and the Digital Terrain Model, Coordinate System GCS, Datum de Lisboa, Hayford-Gauss. The green colour indicates the areas of visibility from Frijão. The settlements that can be seen from the Frijão are: Falperra (4), Ermidas (11) and Facho (12).

\section{AGRADECIMENTOS}

À Doutora Ana M. S. Bettencourt; à empresa Archeo'Estudos - Investigação Arqueológica, Lda., especialmente à Sandra Ralha e à Paula Abrantes; ao Museu Regional de Arqueologia D. Diogo de Sousa (MDSS), Braga, particularmente à Maria Clara Lobo, ao Vítor Hugo Torres, ao Manuel Santos; ao Tiago Pereira pelo tratamento das fotografias; ao Filipe Pereira pela elaboração dos mapas; à Joana Cabo pelo auxílio na escrita em inglês; ao Dr. Gonçalo Cruz e à Doutora Carla Braz Martins por me ajudarem em outras hesitações.

Este trabalho foi realizado no âmbito do projeto de dissertação de Mestrado intitulado A Estação Arqueológica da Idade do Ferro de Frijão (Braga, Norte de Portugal), apresentado à Universidade do Minho, em 2012, e no âmbito de projeto Espaços naturais, arquitecturas, arte rupestre e deposições na pré-história recente da fachada ocidental do centro-norte português: das acções aos significados - ENARDAS (PTDC/HIS-ARQ/112983/2009), financiado pelo Programa Operacional Temático Factores de Competitividade (COMPETE) e comparticipado pelo Fundo Comunitário Europeu FEDER.

\section{BIBLIOGRAFIA}

ALMEIDA, C.A F. 1974. O monumento com forno de Sanfins e as escavações de 1973, III CNA, Porto: 149-172.

AYÁn VILA, X.M. 2011. Casa, Familia y Comunidad en la Edad del Hierro del $N W$. Tese de Doutoramento, Universidade de Santiago de Compostela, Santiago de Compostela.

ARMADA PITA, X.-L. 2005. Formas y rituales de banquete en la Hispania indoeuropea. Tese de Doutoramento, Universidade da Coruña, La Coruña.

ARMADA PITA, X.-L. 2008. ¿Carne, drogas o alcohol? Calderos y banquetes en el Bronce Final de la Península Ibérica. Cuadernos de Prehistoria y Arqueología de la Universidad de Granada 18: 125-162.

ARNOLD, B. 1993. The material culture of social structure: rank and status in early Iron Age. Ann Arbor, Michigan.

Barbosa, R. P. \& Azevedo, M. 2004-05. A antropização da paisagem no vale do Este: dados inéditos para o seu estudo. Mínia 11-12: 113-136. 
Bellino, A. 1909. Cidades Mortas (Estudo Póstumo). O Archeologo Português, Lisboa, $1^{\mathrm{a}}$ série, 14: 1-8.

BetTEnCOURT, A.M.S. 1999. A Paisagem e o Homem na bacia do Cávado durante o II e o I milénios $A C, 5$ vols. Tese de Doutoramento, Universidade do Minho, Braga.

Bettencourt, A.M.S. 2001a. Aspectos da metalurgia do bronze durante a Proto-História do Entre Douro e Minho. Arqueologia 26: 14-46.

Bettencourt, A.M.S. 2001b. O povoado da Santinha, Ama res, Norte de Portugal, nos finais da Idade do Bronze. Cadernos de Arqueologia - Monografias 12. CCHS Unidade de Arqueologia da Universidade do Minho, Braga.

BRANDÃO, A.M. 1889-1892. Apontamentos folklóricos famalicenses. Revista de Guimarães 6, 1889: 182-207; 7 1890: 200-202; 8, 1891: 47-50; 9, 1892: 226-227.

BRUdenell, M. \& COOPER, A. 2008. Post-middenism: depositional histories on Later Bronze Age settlements at broom, Bedfordshire. Oxford Journal of Archaeology 27:15-36

CAlO LOURIDO, F. 1994. A plástica da cultura castrexa galegoportuguesa, Catalogación arqueológica y artística de Galicia del Museo de Pontevedra. Fundación Pedro Barrié de la Maza, A Coruña.

CARVAlHO, H.P.A. 2008. O povoamento romano na fachada ocidental do Conventus Bracarensis. Tese de Doutoramento, Universidade do Minho, Braga.

CARDOSO, M. 1931. A última descoberta arqueológica na Citânia de Briteiros e a interpretação da Pedra Formosa. Revista de Guimarães 41 (1-2) e (3).

CARdoso, M. 1932. A última descoberta arqueológica na Citânia de Briteiros e a interpretação da Pedra Formosa. Revista de Guimarães 42 (1-2) e (3-4)

CARDoso, M. 1972. Catálogo do Museu de Martins Sarmento. Secção de Epigrafia Latina e de Escultura Antiga, ${ }^{2}$ ed, Guimarães.

CAStro, J.S. Correia, S.H; Oliveira, E.P. 1980. O Castrum Maximum (Monte Castro) Braga. Arqueologia e História 2 : 37-53.

CostA, A.C. 1706-1712. Corografia Portugueza e Descripçam Topográfica do Reyno de Portugal, Lisboa, 3 vol. ( 2 ed., Braga, 1868-1869).

CunHA, A.R. 1947. Cividade do Monte das Caldas. Diário do Minho. Braga: 03.11.1947.

CunHA, A. R. 1948. Na Falperra. Diário do Minho. Braga: 09.08.1948.

CUNHA, A.R. 1953-1954. Escavações no oppidum de Santa Marta. Bracara Augusta 5 (1-3): 241-243

CunHA, A.R. 1975. Trepando aos Montes. O Distrito de Braga. $2^{\text {a }}$ Série, Braga.

DINIS, P.A. 1993. Ordenamento do Território do Baixo Ave no I Milénio a.C. Tese de Mestrado, Faculdade de Letras da Universidade do Porto, Porto.

ENCARNAÇÃO, J. 1970. Lápides a divindades indígenas no Museu de Guimarães, Revista de Guimarães 80 (3-4): 207-238.

FeIO, A. 1984. Coisas Memoráveis de Braga. Braga.

FERREIRA, J. 2012. O povoamento no vale do rio Este do Neolítico à Idade Média: estudo preliminar. Relatório de estágio de Mestrado, Universidade do Minho, Braga.

Figueiral, I. (1990). Le Nord-Ouest du Portugal et les modifications de l'ecosysteme, du Bronze Final à l'époque romaine, d'après anthracoanalyse de sites archéologiques, Tese de Doutoramento, Université de Montpellier, Montpellier.

FONTES, L.F.O. 1993. Inventários de sítios arqueológicos de concelho de Braga. Mínia, $3^{\mathrm{a}}$ série, 1, Ano I.

GONZÁleZ RUIBAL, A. 2006. Galaicos poder y comunidad en el noroeste de la Península Ibérica (1200 a.C - 50 d.C.) Brigantium 18, Museo arqueolóxico e histórico castelo de San Antón, A Coruña.

Pautreau, J.P. \& QueIRogA, F.M.V.R. 1990. Le Castro das Ermidas. Village Fortifié du Portugal, Archeologia 253: 44-49.

QueIRogA, F.M.V.R. 1983. Património Histórico de Vila Nova de Famalicão, Boletim Cultural - Vila Nova de Famalicão 4: 47-51.

QUEIROGA, F.M.V.R. 1985a. Vila Nova de Famalicão, Castro de Vermoim - 1982. Informação Arqueológica 5: 56.

QueIroga, F.M.V.R. 1985b. Vila Nova de Famalicão. Castro das Ermidas - 1983. Informação Arqueológica 5: 5657.

QuEIROGA, F.M.V.R. 1985c. Escavações Arqueológicas no Castro das Ermidas - A Campanha de 1983. Boletim Cultural - Vila Nova de Famalicão 6: 5-43.

QueIRogA, F.M.V.R. 1986a. Vila Nova de Famalicão, Castro de Vermoim - 1984, Informação Arqueológica 6: 35.

QueIrogA, F.M.V.R. 1986b. Vila Nova de Famalicão. Castro das Ermidas - Jesufrei - 1984, Informação Arqueológica 6: 35 .

QueIROGA, F.M.V.R. 1987. Corte estratigráfico no castro de Penices, Boletim Cultural - Vila Nova de Famalicão 7 $3-22$

QueIRogA, F.M.V.R. 2003. War and Castros. New approaches to the northwestern Portuguese Iron Age. Archaeopress, Oxford.

MARTINS, M. 1990. O Povoamento proto-histórico e a romanização da bacia do curso médio do Cávado. Caderno de Arqueologia - Monografias 5. Unidade de Arqueologia da Universidade do Minho, Braga

Medeiros, A.C. \& TeiXeIRA, C. 1969. Carta Geológica de Portugal na escala de 1/50 000. Notícia explicativa da folha 5-C. Serviços Geológicos de Portugal. Lisboa.

RALHA, S.S. 2004. Intervenção arqueológica na escavação de empréstimo de Frijão. Zona industral da Cunha Cunha, Braga. Relatório Final. Archeoestudos, Investigação arqueológica, Lda.

SARMENTO, F.M. 1933. A propósito de castros. O Panorama Contemporâneo. Dispersos, 1, Coimbra.

SARMENTO, M. 1970. Antiqua. Revista de Guimarães 80: 5-72; 96.

Silva, A.C.F. 1986. A cultura castreja no Noroeste de Portugal. Câmara Municipal, Paços de Ferreira.

SILVA, A.C.F. 2007. A cultura castreja no Noroeste de Portugal. $2^{\mathrm{a}}$ Edição. Câmara Municipal de Paços de Ferreira Museu Arqueológico da Citânia de Sanfins / Centro de Arqueologia Castreja e Estudos Célticos.

SILVA, V.M.F. 2013 Caldeiro de rebites da Idade do Ferro de Frijão (Braga, Norte de Portugal). Poster apresentado às II Jornadas de Novos Investigadores do Noroeste As novas problemáticas de investigação. Guimarães: Sociedade Martins Sarmento. Consultável em: http:/ enardas.pt/ ou http://uminho.academia.edu/VítorSilva

SouSA, J. 1968-1970. A estação arqueológica da Falperra. Notas para a sua história, Arquivo de Beja (25-27): 57-64.

REY CASTIÑEIRAS, J. 1992. Yacimientos castreños de la vertiente atlántica: análisis de la cerámica indígena. Servicio de Publicaciones e Intercambio Científico de la Universidad de Santiago.

RosÁRIO, A. 1973. Falam documentos, II-III, (31-66), Braga.

VASCONCELOS, J.L. 1897-1905-1913. Religiões da Lusitânia, I (1897), II (1905), III (1913), Lisboa. 